BETRAYAL BLINDNESS QUESTIONNAIRES (BBQs)

Development and Initial Validation of the Betrayal Blindness Questionnaires (BBQs): Past Memory, Current Memory, and Rotating Betrayal Blindness Questionnaires Jennifer M. Gómez, Ph.D., Nelson O. O. Zounlome, Ph.D., Laura K. Noll, Ph.D. Under Review For Publication

20 December 2021 


\begin{abstract}
Emerging adults of Color are at increased risk for interpersonal trauma, including physical, sexual, and emotional abuse (Porter \& Williams, 2011). Understanding victims' awareness of the existence and impact of their own trauma history is important for research and clinical work. However, because of trauma awareness processes (e.g., underreporting), it is challenging to accurately measure awareness of trauma. Based on betrayal trauma theory (Freyd, 1996), the concept of rotating betrayal blindness theorizes that awareness of past trauma may shift across contexts and time (Noll \& Gómez, 2013). The purpose of the current study is to provide an initial validation of the Betrayal Blindness Questionnaires (BBQs) among a sample of emerging adults of Color with trauma histories using exploratory factor analysis (EFA). With its three questionnaires assessing past memory (PM-BBQ), current memory (CM-BBQ), and rotating betrayal blindness (R-BBQ), the BBQs measure the past and present impact of traumatic events, as well as how this impact may vary according to the theory of rotating betrayal blindness. Participants $(N=155)$ were college students of Color who completed the one-hour online survey at a location of their own choosing. Based on the EFA, the R-BBQ retained 19 items across 4 factors, the PM-BBQ retained 22 items across 4 factors, and the CM-BBQ retained 18 items across 4 factors. The questionnaires demonstrated adequate to excellent reliability $(\alpha=.66-.95)$. The BBQs can be used in basic and applied research to better examine nonlinear changes to autobiographical memory for trauma.
\end{abstract}

Key Words: rotating betrayal blindness; trauma memory; scale development, betrayal trauma theory; emerging adults of Color 


\section{Development and Initial Validation of the Betrayal Blindness Questionnaires (BBQs): Past Memory, Current Memory, and Rotating Betrayal Blindness Questionnaires}

Interpersonal trauma, including physical, sexual, and emotional abuse, is prevalent in the general population (e.g., Kilpatrick \& Acierno, 2003), with instantiations of structural racism (e.g., Hicken et al., 2018) and other inequalities putting people of Color, including emerging adults of Color, at increased risk for victimization (Howard et al., 2019; Porter \& Williams, 2011) and revictimization (Classen et al., 2005). Widely recognized as especially damaging (DePrince, Combs, \& Shanahan, 2009; Fisher, 2017), interpersonal trauma is associated with a host of adverse outcomes including significant psychological difficulties (Chen et al., 2010; Goldsmith, Freyd, \& DePrince, 2012) and poor physical health (López et al., 2018). In addition to mental and physical health outcomes, cognitive responses to interpersonal trauma may disrupt autobiographical memory for the abuse, including dissociation, denial, and traumatic amnesia (Freyd, 1996; Adams-Clark et al., 2020). These self-protective patterns of knowledge isolation pose significant methodological challenges to research efforts in this domain. Thus, given the wide-ranging impacts and complexity of trauma awareness processes (Goldsmith, Barlow, \& Freyd, 2004), awareness of interpersonal trauma remains difficult to measure, with false negatives due to memory failure and underreporting being a concern (Freyd et al., 2005). Proposed by Noll and Gómez (2013), the concept of rotating betrayal blindness may help describe and explain such shifts in awareness for interpersonal trauma. However, there remains an absence of measures that capture the way in unawareness of interpersonal trauma may shift (e.g., rotate) over time. Therefore, the purpose of the current study was to develop and validate the Betrayal Blindness Questionnaires (BBQs), with subscales for Past Memory, Current Memory, and Rotating Betrayal Blindness, in a sample of emerging adults of Color. 


\section{Traumatic Amnesia \& Betrayal Blindness}

More than 125 years of interdisciplinary scholarship documents the significant impacts of interpersonal trauma on autobiographical memory and awareness (Freyd, 2005; van der Kolk, 2015). Paralleling the focus of the current study, it is important to note that the field of trauma studies itself has been described as one of periodic remembering and forgetting, which tracks with the ebb and flow of cultural and political events, including war and social justice movements (Burke, 2021; Herman, 1997; van der Kolk, 2015). We argue that such historical changes in the focus on interpersonal trauma are significant for individuals, as they represent powerful contextual factors that likely impact awareness of interpersonal trauma across the lifespan. Within this broad historical context, betrayal trauma theory (BTT; e.g., Freyd, 1996, 1997) is a feminist framework that extends prior fear-based or shattered-assumptions paradigms to situate abuse in the complexities of the interpersonal context (for a recent overview, see Adams-Clark et al., 2020). With a focus on the significance of trust in interpersonal relationships, BTT posits that trauma may be conceptualized along two-dimensions: the extent to which an event evokes fear/terror and the extent to which an event represents a betrayal of interpersonal trust (Freyd, 1996; Figure 1).

Within the BTT framework, high-betrayal events, such as child sexual abuse by a caregiver, are theorized to produce clinically-meaningful differences in long-term outcomes, including failure to recall that the abuse occurred and/or denial that the abuse was significant (DePrince et al., 2012; Freyd, 1996; Freyd, DePrince, \& Gleaves, 2007). In the case of abuse by a parent during childhood, dependency on the parent for survival necessarily places the child in a double-bind, where awareness of the abuse poses a threat to the child's needs for attachment. It is this conflict that may lead to denial of the abuse, or betrayal blindness (Freyd, 1996; Freyd \& 
Birrell, 2013). As such, high-betrayal traumas — particularly those that occur during childhoodare thought to have a profound impact on autobiographical memory (Moore \& Zoellner, 2007), with severe and/or chronic abuse leading to fragmentation and/or structural dissociation of the personality (Fisher, 2017) and amnesia for the interpersonal abuse (Freyd, 1994, 1996). Supporting this, interpersonal trauma has been associated with the dissociative subtype of childhood PTSD (Hagan et al., 2018), as well as dissociation and hallucinations in adulthood (Gómez, 2019a, 2019b, 2021a, 2021b; Gómez \& Freyd, 2017; Gómez et al., 2014). Taken together, although ample empirical research documents the severe impacts of high-betrayal trauma on autobiographical memory and awareness, many measures used to index these effects do not assess the ways in which awareness for trauma may change over time.

\section{Rotating Betrayal Blindness}

The absence of measurement tools assessing changing awareness of interpersonal trauma notwithstanding, extant self-report questionnaires tend to function well, as memory is generally reliable, though certainly malleable (Brewin et al., 2020). However, awareness of interpersonal trauma has been observed to shift over time in response to internal and external factors, such as changes in developmental status, perceptions of psychological or physical safety, access to resources, proximity to a perpetrator of abuse, and/or changing cultural attitudes toward trauma disclosure and abuse (e.g., Goldsmith, Barlow, \& Freyd, 2004; Noll \& Gómez, 2013). According to Noll and Gómez (2013), shifts in memory can be rotational, as the path to knowing one has been traumatically betrayed by a close other is often non-linear and includes qualitative differences in knowing and unknowing that may oscillate back and forth through degrees of meta-cognitive awareness. As such, the phenomenon of intermittent and/or changing unawareness for abuse across time is called rotating betrayal blindness (Noll \& Gómez, 2013). 
Although the exact mechanisms for non-linear shifts in awareness for autobiographicallysignificant events have yet to be fully elucidated - in part due to a dearth of measurement tools designed to index changing awareness for interpersonal trauma — advances in our understanding of the neural underpinnings of memory consolidation have shed light on seemingly contradictory observations in memory studies (e.g., that trauma memories can be especially vivid and intrusive, while awareness of trauma itself can disappear altogether). Changes in one's metacognitive awareness for earlier abuse may help explain some aspects of memory changes over time, such as the experience of suddenly realizing one was abused. For example, in describing seven cases of independently corroborated recovered memories for abuse, Schooler (2008) posits that some of these 'discovered' memories may be understood as changes in meta-awareness for interpersonal trauma. Such changes include gaining a new meta-awareness regarding the meaning of the abuse, regaining prior meta-awareness that may have been avoided for some time, and/or gaining previously non-existent meta-awareness for experiences. These changes may lead to attribution errors regarding the existence or lack thereof of trauma memories at previous points in time. Regardless, such changes alter an individuals' view of their personal history across time and are rarely captured by extant self-report measures that assess experiences of interpersonal abuse.

\section{Purpose of the Study}

Interpersonal trauma is impactful (e.g., Adams-Clark et al., 2020), with emerging of adults of Color at increased risk for victimization (e.g., Porter \& Williams, 2011) due to structural racism (e.g., Hicken et al., 2018) and other instantiations of White Supremacy. Betrayal trauma theory (e.g., Freyd, 1996) provides a framework for understanding the harm of trauma, including disruptions to memory and awareness of abuse, known as betrayal blindness. 
Noll and Gómez (2013) expanded on this concept through introducing rotating betrayal blindness, which serves as a conceptual framework for identifying, examining, and ultimately understanding nonlinear shifts to autobiographical memory for trauma. However, to date, no known measures have assessed rotating betrayal blindness. Therefore, the purpose of the study is to develop and initially validate the Betrayal Blindness Questionnaires (BBQs), with subscales for Past Memory Questionnaire (PM-BBQ)- memory right after the traumatic event, Current Memory Questionnaire (CM-BBQ)- what is remembered presently, and Rotating Betrayal Blindness Questionnaire (R-BBQ)- vacillations in memory, in a sample of emerging adults of Color with trauma histories.

\section{Method}

\section{Participants \& Procedure}

Participants $\left(N=155 ; M_{\text {age }}=20.51\right.$ years, $S D=3.27$ years $)$ were college students of Color at a predominantly white university in the Northwestern United States. The sample was majority women (Women: 62.6\%; Men: 36.8\%; Another Gender Identity: .6\%; Decline to Answer: .3\%) and ethnically diverse, with 34.8\% Asian, 25.2\% Hispanic/Latino American, 16.1\% Other, 15.5\% Black/African American, 3.9\% Native Hawaiian or Other Pacific Islander, 1.9\% American Indian/Alaska Native, and 2.6\% Middle Eastern. All participants endorsed at least one traumatic event, with relatively high rates of physical (38.1\%), sexual (52.3\%), and emotional (81.3\%) abuse (Table 1).

Participants were university students who were members of the Human Subjects Pool through the online SONA system. Students could receive course credit for participating in research or completing comparable alternative research assignments. Potential participants completed a 30-minute pre-screen questionnaire, which resulted in eligible studies — named after 
composers - being listed. This blinded process for studies guards against potential participants selecting studies based on interest in the topic, thus providing a more random sample. The prescreen item for the current data collection was "I identify as an ethnic minority." Participants accessed the consent form online, and after clicking "Agree" at the bottom of the page, completed the 60-minute online survey at a location of their own choosing. Measures were not counter-balanced because beginning with trauma measures is considered to be least stressful for participants (Nijenhuis, van der Hart, \& Kruger, 2002). Participants could decline to answer any question without penalty. Participants were shown the debriefing form at the end of the survey, which included the purpose of the study, contact information for the researchers, and a list of mental health resources in the local community. The University of Oregon Institutional Review Board (IRB) approved the current data collection (protocol number: 08102014.012).

Development of the BBQs. After consulting with the relevant literature on betrayal trauma, rotating betrayal blindness, and memory (e.g., Freyd, 1996; Noll \& Gómez, 2013; Schooler, 2008) and receiving feedback from informal presentations to colleagues, \{two of the authors; masked for peer review designed the Betrayal Blindness Questionnaires (BBQs), with three separate questionnaires with parallel items: Past Memory Questionnaire (PM-BBQ)memory right after the traumatic event $(N=33)$, Current Memory Questionnaire (CM-BBQ)what is remembered presently $(N=33)$, and Rotating Betrayal Blindness Questionnaire (RBBQ)- vacillations in memory $(N=33)$. In this creation, \{two of the authors; masked for peer review s created items to address the domains of intrusion/all-consuming-ness, memory control, dissociative amnesia, and situation-dependence. Additionally, meetings with all study authors served to retain or exclude items based on conceptual frameworks. Exploratory factor analyses (EFA) and internal consistency as measured by Cronbach's alpha were run. Finally, study 
authors independently created labels and descriptions for factors within each measure, then came together to reach consensus on final conceptualizations of the questionnaires and related factors.

\section{Measures}

These data are part of a larger study (author citations); therefore, only the measures used in the current analysis are included here. A complete list of measures can be found here: [removed for masked review]

Brief Betrayal Trauma Survey Modified (BBTS-M). The BBTS-M (Goldberg \& Freyd, 2006) is a 12-item self-report questionnaire that assesses for physical, sexual, and emotional abuse perpetrated by close (high betrayal) and un-close (medium betrayal) others of the same ethnicity (ethno-cultural betrayal) or of a different ethnicity (interracial). Items are rated on a sixpoint Likert scale from never to more than 100 times. A sample item is: "You were deliberately attacked so severely as to result in marks, bruises, blood, broken bones, or broken teeth by someone of your same ethnicity with whom you were very close.” In its initial validation, the completed measure yielded good test re-test reliability for childhood items [83\%] and adulthood items [75\%] (Goldberg \& Freyd, 2006). A test of internal consistency is not appropriate for this measure given that the BBTS-M assesses for frequency of different events, as opposed to a latent construct, such as depression.

\section{Past Memory Questionnaire-Betrayal Blindness Questionnaires (PM-BBQ).}

Created by \{two of the authors; masked for peer review $\}$ for the current study, the pre-validated PM-BBQ has 33 items to measures memory and impact directly following the trauma. Participants were given the instructions: Think back to the event(s) you reported experiencing. Please indicate to what extent the following statements describe your experience of that event(s) at the time of the event(s) and for the period right after it happened. Item responses were 0 
(Never true for me) to 3 (Always true for me) with greater scores indicating higher impact of past trauma. The PM-BBQ has four subscales: Focus (8 items), which entail past focus on trauma through memory, cognitions, decision-making, and identity; Trauma Denial (6 items), detailing past unawareness of outright and intermittent trauma; Insignificant and Unimportant Trauma Appraisals (4 items), delineating past trauma appraisals as insignificant and unimportant; and Failure to Remember (4 items) which entails Past failure to remember trauma. An example item is, "At the time of the event(s) and for the period right after it happened, the event(s) was often the focus of my thoughts.” For the subscales (Focus, Trauma Denial, Insignificant and Unimportant Trauma Appraisals, and Failure to Remember), we found alphas of .93, .85, .87, and .84 . We found an alpha of .67 for this scale.

\section{Rotating Current Memory Questionnaire-Betrayal Blindness Questionnaires (CM-}

BBQ). Created by \{two of the authors; masked for peer review\} for the current study, the original CM-BBQ includes 33 items to capture the current memory and impact of the trauma. Participants were prompted with the instructions: Think back to this same event(s) you reported. Please indicate to what extent the following statements describe your experience of that event(s) NOW. Item responses were 0 (Never true for me) to 3 (Always true for me) with higher scores indicating greater current impact of trauma. The CM-BBQ has four subscales: Influential (6 items), which captures what extent currently, the event(s) is a rememberable, influential, dominant part of life; Wanton Disbelief (4 items), describing the current avoidance, denial, and want for the event(s) not have happened; Unawareness (4 items), detailing participants current inability to remember the event(s) fully; and Not Important (4 items) which entails people current inability to remember the event(s) fully. An example item is, "Now, the event(s) is often the focus of my thoughts." For the subscales (Influential, Wanton Disbelief, Unawareness, and 
Not Important), we found alphas of $.88, .73, .79$, and .78 , respectively. We obtained an alpha of .66 for the overall scale.

\section{Rotating Betrayal Blindness Questionnaire-Betrayal Blindness Questionnaire (R-}

BBQ). Created by \{two of the authors; masked for peer review $\}$ for the current study, the prevalidated R-BBQ measures vacillations in memory and impact of the trauma with 33 items. Participants were prompted with the instructions: Think back to this same event(s) you reported. Please indicate how much you agree with the following statements. Item responses were 0 (Strongly Disagree) to 3 (Strongly Agree) with higher scores indicating greater changes in their relationship to their trauma. The R-BBQ has four subscales: Significance (5 items), which delineates changes to the appraisals of the importance of the event changes over time; Memories (6 items), describing changes to intrusion, avoidance, and contextual reminders over time; Awareness (4 items), detailing changes in partial and full awareness of the event; and Remembering (4 items) which entails changes in how easy it is to remember the event, globally and specifically over time. An example item is, "Since the event(s), there have been times when the event(s) was all consuming AND other times when it was not all consuming." For the subscales (Significance, Memories, Awareness, and Remembering), we found alphas of .91, .88, .90 , and .87 , respectively. We obtained an alpha of .95 for the overall scale.

\section{Results}

\section{Exploratory Factor Analysis Results}

We used the Kaiser-Meyer-Olkin (KMO) measure of sampling adequacy and Bartlett's Test of Sphericity to examine if the three measures were suitable for factor analysis. The KMO for the PM-BBQ, CM-BBQ, and R-BBQ were .87, .85, and .91, respectively, and the Bartlett's Test were 3605.758 (528), $\mathrm{p}<.0001,3588.360$ (528), $\mathrm{p}<.0001$, and 4309.868 (528), $\mathrm{p}<.0001$, 
respectively. These findings indicated that the data for all three scales were appropriate for factoring (Tabachnick \& Fidell, 2001). Because we anticipated the factors in each scale to be correlated with one another, we employed an exploratory factor analysis (EFA) using Principle Axis Factoring (PAF) with Promax rotation (oblique rotational approach).

We utilized both a visual scree test (Cattell, 1966) and parallel analysis (Hayton, Allen, \& Scarpello, 2004; O'Connor, 2000) to inform factor retention. We retained factors if the eigenvalue values were higher than the $95^{\text {th }}$ percentile (parallel analysis) and the point at which the last significant break occurred (scree plot). For the PM-BBQ, five factors were suggested based on the parallel analysis, five factors were suggested for the CM-BBQ, and four factors were suggested for the R-BBQ. The scree plot suggested five factors for the PM-BBQ, four for the CM-BBQ, and three factors for the R-BBQ. Subsequently, item selection was based on: (a) factor loading greater than .40 , (b) no cross-loadings that exceed .20 , (c) items that made conceptual sense as determined by the authors, and (d) internal consistency estimates greater .65. Taking this approach, we retained 22 items for the PM-BBQ, 18 items for the CM-BBQ, and 19 items for the R-BBQ (see Tables 2-4).

The PM-BBQ has four subscales: Focus, Trauma Denial, Insignificant and Unimportant Trauma Appraisals, and Failure to Remember (author citation, 2021). Focus captures past focus on trauma through memory, cognitions, decision-making, and identity; Trauma Denial measures past unawareness of outright and intermittent trauma; Insignificant and Unimportant Trauma Appraisals captures past trauma appraisals as insignificant and unimportant; and Failure to Remember measures past failure to remember trauma. An example item is, "At the time of the event(s) and for the period right after it happened, the event(s) was often the focus of my thoughts." 
The CM-BBQ has four subscales: Influential, Wanton Disbelief, Unawareness, and Not Important (author citation, 2021). Influential focuses on what extent currently, the event(s) is a remember-able, influential, dominant part of life; Wanton Disbelief measures the current avoidance, denial, and want for the event(s) not have happened; Unawareness captures one's current inability to remember the event(s) fully; and Not Important measures one's current inability to remember the event(s) fully. An example item is, "Now, the event(s) is often the focus of my thoughts." Lastly, the R-BBQ has four subscales: Significance, Memories, Awareness, and Remembering (author citation, 2021). Significance outlines changes to the appraisals of the importance of the event changes over time; Memories examines changes to intrusion, avoidance, and contextual reminders over time; Awareness evaluates changes in partial and full awareness of the event; and Remembering captures changes in how easy it is to remember the event, globally and specifically over time. An example item is, "Since the event(s), there have been times when the event(s) was all consuming AND other times when it was not all consuming."

\section{Discussion}

Memory can shift over time in response to internal and external factors (Brewin et al., 2020). Grounded in betrayal trauma theory (e.g., Freyd, 1996), the concept of rotating betrayal blindness conceptualizes nonlinear changes to memory and impact of traumatic events across time and situations (Noll \& Gómez, 2013). The purpose of the current study was to develop and validate the initial psychometric properties of the Betrayal Blindness Questionnaires (BBQs), with three questionnaires: Past Memory Questionnaire (PM-BBQ), Current Memory Questionnaire (CB-BBQ), and Rotating Betrayal Blindness Questionnaire (R-BBQ). Among a sample of emerging adults of Color, we found the three scales and their respective factors to be 
conceptually consistent with rotating betrayal blindness (Noll \& Gómez, 2013), while demonstrating sound psychometric properties with adequate internal consistency. The PM-BBQ has four subscales: Focus, Trauma Denial, Insignificant and Unimportant Trauma Appraisals, and Failure to Remember. The CM-BBQ also has four subscales: Influential, Wanton Disbelief, Unawareness, and Not Important. Lastly, the R-BBQ has four subscales: Significance, Memories, Awareness, and Remembering. As such, the BBQs provide measurement of individuals' awareness, including vacillating awareness, of their trauma histories. From the current study, the BBQs theoretically and methodologically build upon betrayal trauma theory (e.g., Freyd, 1996), including the concept of rotating betrayal blindness (Noll \& Gómez, 2013), by creating a self-report measurement tool to empirically examine past, current, and rotating memory and perceived impact of past trauma events.

Beyond BTT (e.g., Freyd, 1996), the BBQs further contribute to broader memory and interpersonal trauma literatures by providing researchers with a tool to document self-reported variations in awareness of interpersonal abuse experiences across time. Though this complex, multidimensional phenomenon (Goldsmith et al., 2004) is well-described by practitioners treating survivors of abuse (e.g., Fisher, 2017), it is inadequately studied due to a dearth of measures designed to assess for memory fluctuations. By focusing on the dynamic nature of memory shifts across time, the BBQs represent a complementary self-report inventory that can augment the utility of research questionnaires designed to assess experiences of interpersonal trauma and adverse outcomes associated with abuse. As the nonlinear path of awareness is assessed from the perspective of the person victimized, findings from the BBQs can powerfully move the field beyond "Were you abused or not?" to more nuanced understanding of the complicated nature in which traumatic memory is understood. This increased understand then 
necessarily has impacts for how prevalence and impact of trauma are measured, thereby advancing the field's understanding of cognitive and emotional adaptations to traumatic events.

\section{Clinical Implications}

Although the BBQs were developed as a tool for interpersonal trauma research, they may also have implications for clinical practice, including informing assessment and interventions for victims of trauma. Specifically, extant research suggests the myriad ways that individuals may underreport traumatic experiences (e.g., Freyd et al., 2005) and/or minimize the impact of the abuse (e.g., betrayal blindness; Freyd, 1996). Therefore, the BBQs may help clinicians better understand the nuances of nonlinear changes to awareness and impact of trauma across time, thus aiding in trauma-informed care (e.g., Cloitre, 2015; Gómez et al., 2016). At present, no known measures about trauma, memory, and impact differentiate awareness using the rotating betrayal blindness paradigm (Noll \& Gómez, 2013)—assessing the past and present experiences of knowledge isolation of the abuse and/or its impact, as well as the phenomenon of increased awareness in certain circumstances and decreased awareness in others.

This lack of specificity has implications for the setting of therapy in particular. For instance, for those who have been abused by person(s) in power, a therapist's office may represent a similar context, thus resulting in increased betrayal blindness (Freyd, 1996). By having a tool that normalizes such rotating betrayal blindness (Noll \& Gómez, 2013), both clinicians and clients may be more comfortable sitting with uncertainties around abuse, while effectively continuing therapy. Furthermore, the BBQs can aid in clinicians' trauma literacy, while providing context for instances that seem counterintuitive, such as a client with no disclosed trauma history returning from a visit to family with new (or new to the therapist) awareness of the trauma that happened in the home. Additionally, the traumatic event in question 
could be used to assess changing levels of awareness across traumas (e.g., child sexual abuse; adult sexual harassment; adolescent racial discrimination, etc.). Taken together, the BBQs may aid in creating a more culturally humble environment for clients of Color to discuss their traumatic experiences given that victimization occurred within the context of systematic oppression and racism (Bryant-Davis \& Ocampo, 2005; French et al., 2020; Gómez \& Gobin, 2020; Mosley et al., 2020).

\section{Limitations and Future Directions}

Future work needs to build upon the limitations of the current study to bring the BBQs potential impact to fruition. Specifically, future work should examine the BBQs criterion-related validity, test re-test reliability, structure using confirmatory factor analyses, and bi-factor analyses on the subscales we have preliminarily identified in the current study. Furthermore, future research can do bi-factor analyses If shown to be statically validated, the BBQs has the potential to be used in larger-scale studies evaluating the impact of variations in awareness of trauma history across time and contexts, especially among people of Color. Additionally, future research should explore the mental and physical health trajectories of rotating betrayal blindness (Noll \& Gómez, 2013) and nonlinear memory for and the perceived impact of traumatic events. Finally, the BBQs should be validated within diverse samples, including within and across genders, ethnicities, and clinical populations.

\section{Concluding Thoughts}

While deliberating centralizing emerging adults of Color, the current study contributes the theoretical concept of rotating betrayal blindness (RBB; Noll \& Gómez, 2013) based on Freyd's (1996) betrayal trauma theory and methodological avenue for assessing RBB through the initial validation of the Betrayal Blindness Questionnaires (BBQs). As such, we further 
contribute to the literature by conceptualizing and identifying nonlinear shifts in traumatic memory across time. As such, we hope for the BBQs to be used to contribute to the field's understanding of autobiographical memory for trauma. 


\section{References}

Author Citation (2021). Betrayal Blindness Questionnaires. Open Science Framework. https://osf.io/578s4/?view_only=d7ad443a914f462ab9afdc11f7bf6f96

Brewin, C. R., Andrews, B., \& Mickes, L. (2020). Regaining consensus on the reliability of memory. Current Directions in Psychological Science, 29(2), 121-125. https://doi.org/10.1177/0963721419898122

Bryant-Davis, T., \& Ocampo, C. (2005). Racist incident-based trauma. The Counseling Psychologist, 33(4), 479-500. https://10.1177/0011000005276465

Cattell R. B. (1966). The Scree test for the number of factors. Multivariate Behavioral Research, 1, 245-276. http://10.1207/s15327906mbr0102_10

Cloitre, M. (2015). The "one size fits all” approach to trauma treatment: Should we be satisfied?. European Journal of Psychotraumatology, 6(1), 27344. https://doi.org/10.3402/ejpt.v6.27344

DePrince, A.P, Brown, L.S., Cheit, R.E., Freyd, J.J., Gold, S.N., Pezdek, K. \& Quina, K (2012). Motivated forgetting and misremembering: Perspectives from Betrayal Trauma Theory. In Belli, R. F. (Ed.), True and False Recovered Memories: Toward a Reconciliation of the Debate (Nebraska Symposium on Motivation 58) (pp 193-243). New York, NY: Springer.

DePrince, A. P., Combs, M. D., \& Shanahan, M. (2009). Automatic relationship-harm associations and interpersonal trauma involving close others. Psychology of Women Quarterly, 33(2), 163-171.

Fisher, J. (2017). Healing the fragmented selves of trauma survivors: Overcoming internal selfalienation. Oxfordshire, UK: Routledge. 
French, B. H., Lewis, J. A., Mosley, D. V., Adames, H. Y., Chavez-Dueñas, N. Y., Chen, G. A., \& Neville, H. A. (2020). Toward a psychological framework of radical healing in communities of color. The Counseling Psychologist, 48(1), 14-46. https://doi.org/10.1177/0011000019843506

Freyd, J. J. (1996). Betrayal trauma: The logic of forgetting childhood abuse. Cambridge, MA: Harvard University Press.

Freyd, J. J. (1997). Violations of power, adaptive blindness, and betrayal trauma theory. Feminism Psychology, 7(1), 22-32. https://doi.org/10.1177/0959353597071004

Freyd, J. J., \& Birrell, P. J. (2013). Blind to betrayal. New York, NY: Wiley.

Freyd, J. J., DePrince, A. P., \& Gleaves, D. (2007). The state of betrayal trauma theory: Reply to McNally (2007) - Conceptual issues and future directions. Memory, 15(3), 295-311. https://doi.org/ 10.1080/09658210701256514

Freyd, J. J., Putnam, F. W., Lyon, T. D., Becker-Blease, K. A., Cheit, R. E., Siegel, N. B., \& Pezdek, K. (2005). The science of child sexual abuse. Science, 308, 501.

Goldberg, L. R., \& Freyd, J. J. (2006). Self-reports of potentially traumatic experiences in an adult community sample: Gender differences and test-retest stabilities of the items in a brief betrayal-trauma survey. Journal of Trauma \& Dissociation, 7(3), 39-63. https://doi.org/10.1300/J229v07n03 04

Goldsmith, R. E., Barlow, M. R., \& Freyd, J. J. (2004). Knowing and not knowing about trauma: Implications for therapy. Psychotherapy: Theory, Research, Practice, Training, 41(4), 448-463. https://doi.org/ 10.1037/0033-3204.41.4.448 
Goldsmith, R. E., Freyd, J. J., \& DePrince, A. P. (2012). Betrayal trauma: Associations with psychological and physical symptoms in young adults. Journal of Interpersonal Violence, 27(3), 547-567. https://doi.org/10.1177/0886260511421672

Gómez, J. M. (2019a). High betrayal adolescent sexual abuse and non-suicidal self-injury: The role of depersonalization in emerging adults. Journal of Child Sexual Abuse, 28, 318-332. https://doi.org/10.1080/10538712.2018.1539425

Gómez, J. M. (2019b). What's in a betrayal? Trauma, dissociation, and hallucinations among high-functioning ethnic minority emerging adults. Journal of Aggression, Maltreatment \& Trauma, 28(10), 1181-1198. https://doi.org/10.1080/10926771.2018.1494653

Gómez, J. M. (2021a). Does gender matter? An exploratory study of cultural betrayal trauma and hallucinations in Latino undergraduates at a predominantly White university. Journal of Interpersonal Violence, 36(3-4), NP1375-1390NP. https://doi.org/10.1177/0886260517746942

Gómez, J. M. (2021b). Gendered sexual violence: Betrayal trauma, dissociation, \& PTSD in diverse college students. Journal of Aggression, Maltreatment, \& Trauma Special Issue: Sexual Violence \& Trauma Among Diversity Populations, 30(5), 625-640. https://10.1080/10926771.2020.1783737

Gómez, J. M., \& Freyd, J. J. (2017). High betrayal child sexual abuse and hallucinations: A test of an indirect effect of dissociation. Journal of Child Sexual Abuse, 26, 507-518. https://10.1080/10538712.2017.1310776

Gómez, J. M., \& Gobin, R. L. (2020). Black women and girls \& \#MeToo: Rape, cultural betrayal, \& healing. Sex Roles: A Journal of Research, 82, 1-12. https://doi.org/10.1007/s11199-019-01040-0 
Gómez, J. M., Kaehler, L. A., \& Freyd, J. J. (2014). Are hallucinations related to betrayal trauma exposure? A three-study exploration. Psychological Trauma: Theory, Research, Practice, \& Policy, 6, 675-682. https://doi.org/10.1037/a0037084

Gómez, J. M., Lewis, J. K, Noll, L. K., Smidt, A. M., \& Birrell, P. J. (2016). Shifting the focus: Nonpathologizing approaches to healing from betrayal trauma through an emphasis on relational care. Journal of Trauma \& Dissociation [Special Section], 17, 165-185. https://doi.org/10.1080/15299732.2016.1103104

Hagan, M. J., Gentry, M., Ippen, C. G., \& Lieberman, A. F. (2018). PTSD with and without dissociation in young children exposed to interpersonal trauma. Journal of Affective Disorders, 227, 536-541. https://doi.org/10.1016/j.jad.2017.11.070

Hayton J. C., Allen D. G., \& Scarpello V. (2004). Factor retention decisions in exploratory factor analysis: A tutorial on parallel analysis. Organizational Research Methods, 7, 191-205. http://10.1177/1094428104263675

Herman, J. (1997). Trauma and Recovery. New York, NY: Basic Books.

Hicken, M. T., Kravitz-Wirtz, N., Durkee, M., \& Jackson, J. S. (2018). Racial inequalities in health: Framing future research. Social Science \& Medicine, 199, 11-18. https://doi.org/10.1016/j.socscimed.2017.12.027

Howard, R. M., Potter, S. J., Guedj, C. E., \& Moynihan, M. M. (2019). Sexual violence victimization among community college students. Journal of American College Health, 67(7), 674-687. https://doi.org/10.1080/07448481.2018.1500474

Kilpatrick, D. G., \& Acierno, R. (2003). Mental health needs of crime victims: Epidemiology and outcomes. Journal of Traumatic Stress, 16(2), 119-132. 
López-Martínez, A. E., Serrano-Ibáñez, E. R., Ruiz-Párraga, G. T., Gómez-Pérez, L., RamírezMaestre, C., \& Esteve, R. (2018). Physical health consequences of interpersonal trauma: A systematic review of the role of psychological variables. Trauma, Violence, \& Abuse, 19(3), 305-322.

Moore, S. A., \& Zoellner, L. A. (2007). Overgeneral autobiographical memory and traumatic events: An evaluative review. Psychological Bulletin, 133(3), 419-437. https://doi.org/10.1037/0033-2909.133.3.419

Noll, L. K., \& Gómez, J. M. (2013). Rotating betrayal blindness and the non-linear path to knowing. In Blind to Betrayal. https://sites.google.com/site/ betrayal book/betrayalresearch-news/rotatingbetrayal-blindness-and-the-nonlinear-path-to-knowing

Connor, B. P. (2000). SPSS and SAS programs for determining the number of components using parallel analysis and Velicer's MAP test. Behavior Research Methods, Instruments, \& Computers, 32, 396-402. https://10.3758/BF03200807

Porter, J., \& McQuiller Williams, L. (2011). Intimate violence among underrepresented groups on a college campus. Journal of Interpersonal Violence, 26, 3210-3224. https://doi.org/10.1177/0886260510393011

Schooler, J. W. (2001). Discovering memories of abuse in the light of meta-awareness. Journal of Aggression, Maltreatment \& Trauma, 4(2), 105-136. https://doi.org/10.1300/J146v04n02 06

Tabachnick, B. G., \& Fidell, L., S. (2001). Using multivariate statistics. Needham Heights, MA, Allyn \& Bacon.

Van der Kolk, B. A. (2015). The body keeps the score: Brain, mind, and body in the healing of trauma. New York: NY: Penguin Books. 


\section{Table 1}

Prevalence Rates of Physical, Sexual, and Emotional Abuse Among Emerging Adults of Color with Trauma Histories

\begin{tabular}{lcccc}
\hline & Total & $\begin{array}{c}\text { Young } \\
\text { Women } \\
\mathbf{\%}\end{array}$ & $\begin{array}{c}\text { Young } \\
\text { Men } \\
\mathbf{\%}\end{array}$ & $\chi^{\mathbf{2}}$ \\
& $\mathbf{( N )}$ & $\mathbf{( N )}$ & $\mathbf{( N )}$ & $(\mathbf{1})$ \\
\hline Physical Abuse & $38.1 \%$ & $26.8 \%$ & $56.9 \%$ & $13.94 * * *$ \\
& $(59)$ & $(26)$ & $(33)$ & \\
\hline Sexual Abuse & $52.3 \%$ & $56.7 \%$ & $44.8 \%$ & 2.05 \\
& $(81)$ & $(55)$ & $(26)$ & \\
\hline Emotional Abuse & $81.3 \%$ & $84.5 \%$ & $74.1 \% \%$ & 2.51 \\
& $(126)$ & $(82)$ & $(43)$ & \\
\hline
\end{tabular}

$* * * p<.001$ 


\section{Table 2}

Descriptive Statistics and Factor Loadings for the Past Memory Questionnaire (PM-BBQ)

\begin{tabular}{|c|c|c|c|c|c|c|c|}
\hline \multirow{3}{*}{ \# } & & Des & iptives & $\mathrm{Fac}$ & Loadir & & \\
\hline & \multirow{2}{*}{\multicolumn{7}{|c|}{ Item }} \\
\hline & & & & & & & \\
\hline 5 & $\begin{array}{l}\text { At the time of the event(s) and for the period right after it } \\
\text { happened, the event(s) was often the focus of my thoughts. }\end{array}$ & 3.04 & 1.05 & 0.95 & & & \\
\hline 6 & $\begin{array}{l}\text { At the time of the event(s) and for the period right after it } \\
\text { happened, the event(s) was very important to me. }\end{array}$ & 3.14 & 1.00 & 0.85 & & & \\
\hline 13 & $\begin{array}{l}\text { At the time of the event(s) and for the period right after it } \\
\text { happened, the event(s) was all consuming. }\end{array}$ & 3.29 & 0.99 & 0.89 & & & \\
\hline 2 & $\begin{array}{l}\text { At the time of the event(s) and for the period right after it } \\
\text { happened, the event(s) was part of my identity. }\end{array}$ & 3.47 & 0.88 & 0.69 & & & \\
\hline 12 & $\begin{array}{l}\text { At the time of the event(s) and for the period right after it } \\
\text { happened, the event(s) affected my decision-making. }\end{array}$ & 3.21 & 0.92 & 0.79 & & & \\
\hline 14 & $\begin{array}{l}\text { At the time of the event(s) and for the period right after it } \\
\text { happened, I couldn't help but remember the event(s). }\end{array}$ & 3.13 & 1.34 & 0.95 & & & \\
\hline 17 & $\begin{array}{l}\text { At the time of the event(s) and for the period right after it } \\
\text { happened, I couldn't stop remembering the event(s) even if I } \\
\text { tried. }\end{array}$ & 3.31 & 1.01 & 0.80 & & & \\
\hline 9 & $\begin{array}{l}\text { At the time of the event(s) and for the period right after it } \\
\text { happened, I tried to avoid remembering the event(s). } \\
\text { Trauma Denial }\end{array}$ & 3.16 & 0.99 & 0.55 & & & \\
\hline 22 & $\begin{array}{l}\text { At the time of the event(s) and for the period right after it } \\
\text { happened, there were times I believed the event(s) didn't happen. }\end{array}$ & 1.40 & 0.70 & & 0.62 & & \\
\hline 18 & $\begin{array}{l}\text { At the time of the event(s) and for the period right after it } \\
\text { happened, part of me was aware the event(s) happened but part of } \\
\text { me wasn't. }\end{array}$ & 1.44 & 0.70 & & 0.73 & & \\
\hline 15 & $\begin{array}{l}\text { At the time of the event(s) and for the period right after it } \\
\text { happened, if asked I would have said the event(s) didn't happen. }\end{array}$ & 1.66 & 1.04 & & 0.63 & & \\
\hline 7 & $\begin{array}{l}\text { At the time of the event(s) and for the period right after it } \\
\text { happened, I wanted to believe the event(s) didn't happen. }\end{array}$ & 1.81 & 1.07 & & 0.51 & & \\
\hline
\end{tabular}


8 At the time of the event(s) and for the period right after it happened, I knew the event(s) happened but on some level I

$1.39 \quad 0.78$ didn't know.

$4 \quad$ At the time of the event(s) and for the period right after it happened, I was consciously aware the event(s) happened but not $\quad 1.53 \quad 0.8$ emotionally connected to it.

\section{Insignificant and Unimportant Trauma Appraisals}

3 At the time of the event(s) and for the period right after it happened, the event(s) was insignificant.

16 At the time of the event(s) and for the period right after it happened, I thought the event(s) didn't have an effect on me.

21 At the time of the event(s) and for the period right after it happened, the event(s) really didn't have an effect on me.

10 At the time of the event(s) and for the period right after it happened, the event(s) was not important.

\section{Failure to Remember}

19 At the time of the event(s) and for the period right after it happened, I didn't remember the event(s) but was told it happened $1.15 \quad 0.45$

$\begin{array}{lll}1.43 & 0.70 & 0.73 \\ 1.71 & 0.85 & 0.82 \\ 1.53 & 0.83 & 0.84 \\ 1.48 & 0.83 & 0.73\end{array}$
by someone else.

1 At the time of the event(s) and for the period right after it happened, sometimes I tried to remember the event(s) but couldn't.

11 At the time of the event(s) and for the period right after it happened, I tried to remember the details of the event(s) but I couldn't.

20 At the time of the event(s) and for the period right after it happened, sometimes I wanted to remember the event(s) but I couldn't.

Note. Each item in the PM-BBQ has the stem: "Think back to the event(s) you reported experiencing. Please indicate to what extent the following statements describe your experience of that event(s)(s) AT THE TIME OF THE EVENT(S)(S) AND FOR THE PERIOD RIGHT AFTER IT HAPPENED... 
Table 3

Descriptive Statistics and Factor Loadings for the Rotating Current Memory Questionnaire (CM-BBQ)

\begin{tabular}{|c|c|c|c|c|c|c|c|}
\hline \multirow[b]{2}{*}{ \# } & \multirow[b]{2}{*}{ Item } & \multicolumn{2}{|c|}{ Descriptives } & \multicolumn{4}{|c|}{ Factor Loadings } \\
\hline & & $M$ & $S D$ & F1 & F2 & F3 & F4 \\
\hline & Influential & & & & & & \\
\hline 17 & Now, the event(s) is often the focus of my thoughts. & 3.56 & 0.7 & 0.68 & & & \\
\hline 18 & Now, the event(s) is very important to me. & 3.29 & 0.95 & 0.78 & & & \\
\hline 15 & Now, the event(s) is all consuming. & 3.68 & 0.67 & 0.61 & & & \\
\hline 10 & Now, the event(s) is part of my identity. & 3.24 & 0.99 & 0.74 & & & \\
\hline 6 & Now, the event(s) affects my decision-making. & 3.33 & 0.81 & 0.65 & & & \\
\hline 2 & $\begin{array}{l}\text { Now, I can't stop remembering the event(s) even if I tried. } \\
\text { Wanton Disbelief }\end{array}$ & 3.48 & 0.85 & 0.67 & & & \\
\hline 12 & Now, there are times I believe the event(s) didn't happen. & 1.28 & 0.64 & & 0.57 & & \\
\hline 1 & $\begin{array}{l}\text { Now, part of me is aware the event(s) happened but part of } \\
\text { me isn't. }\end{array}$ & 1.31 & 0.65 & & 0.55 & & \\
\hline 5 & Now, if asked I would have said the event(s) didn't happen. & 1.47 & 0.87 & & 0.63 & & \\
\hline 3 & $\begin{array}{l}\text { Now, I want to believe the event(s) didn't happen. } \\
\text { Unawareness }\end{array}$ & 1.68 & 1.07 & & 0.72 & & \\
\hline 14 & $\begin{array}{l}\text { Now, I don't remember the event(s) but was told it happened } \\
\text { by someone else. }\end{array}$ & 1.20 & 0.56 & & & 0.62 & \\
\hline 13 & Now, sometimes I try to remember the event(s) but can't. & 1.27 & 0.56 & & & 0.65 & \\
\hline 4 & Now, I try to remember the details of the event(s) but I can't. & 1.44 & 0.71 & & & 0.50 & \\
\hline 8 & $\begin{array}{l}\text { Now, sometimes I want to remember the event(s) but I can't. } \\
\text { Not Important }\end{array}$ & 1.28 & 0.56 & & & 0.81 & \\
\hline 7 & Now, the event(s) is insignificant. & 1.79 & 1.02 & & & & 0.80 \\
\hline 11 & Now, the event(s) really didn't have an effect on me. & 1.51 & 0.91 & & & & 0.59 \\
\hline 9 & Now, the event(s) is not important. & 1.71 & 1.08 & & & & 0.87 \\
\hline 16 & $\begin{array}{l}\text { Now, I am consciously aware the event(s) happened but not } \\
\text { emotionally connected to it. }\end{array}$ & 1.55 & 0.83 & & & & 0.46 \\
\hline
\end{tabular}


Note. Each item in the CM-BBQ has the stem: "Think back to this same event(s) you reported. Please indicate to what extent the following statements describe your experience of that event(s) NOW..."

\section{Table 4}

Descriptive Statistics and Factor Loadings for the Rotating Betrayal Blindness Questionnaire (R-BBQ)

\begin{tabular}{|c|c|c|c|c|c|c|c|}
\hline & & Desc & iptives & Facto & Load & & \\
\hline$\#$ & Item & $M$ & $S D$ & F1 & $\mathrm{F} 2$ & F3 & $\mathrm{F} 4$ \\
\hline & Significance & & & & & & \\
\hline 5 & $\begin{array}{l}\text { Since the event(s), there have been times when I } \\
\text { considered it to be insignificant AND other times when } \\
\text { I considered it to be significant. }\end{array}$ & 1.92 & 1.02 & 0.81 & & & \\
\hline 8 & $\begin{array}{l}\text { Since the event(s), my beliefs about whether the } \\
\text { event(s) had an effect on me have changed over time. }\end{array}$ & 2.20 & 1.09 & 0.65 & & & \\
\hline 10 & $\begin{array}{l}\text { Since the event(s), there have been times when I } \\
\text { believed the event(s) really didn't have an effect on me } \\
\text { AND other times when I believed it did really have an } \\
\text { effect on me. }\end{array}$ & 2.09 & 1.06 & 0.86 & & & \\
\hline 7 & $\begin{array}{l}\text { Since the event(s), there have been times when the } \\
\text { event(s) was part of my identity AND other times when } \\
\text { the event(s) was not part of my identity. }\end{array}$ & 1.81 & 0.96 & 0.47 & & & \\
\hline 12 & $\begin{array}{l}\text { Since the event(s), there have been times when I believe } \\
\text { the event(s) was not important to me AND other times } \\
\text { when I believe the event(s) was important to me. } \\
\text { Memories }\end{array}$ & 1.96 & 0.99 & 0.92 & & & \\
\hline 16 & $\begin{array}{l}\text { Since the event(s), there have been times when the } \\
\text { event(s) was all consuming AND other times when it } \\
\text { was not all consuming. }\end{array}$ & 1.91 & 1.06 & & 0.53 & & \\
\hline 14 & $\begin{array}{l}\text { Since the event(s), there have been times when I } \\
\text { couldn't stop remembering the event(s) even if I tried } \\
\text { AND other times when I could stop remembering the }\end{array}$ & 1.73 & .88 & & 0.83 & & \\
\hline
\end{tabular}


19 Since the event(s), there have been times when I tried to avoid remembering the event(s) AND other times when I did not try to avoid remembering the event(s).

11 Since the event(s), there have been times when, if asked, I would say the event(s) didn't happen AND other times when, if asked, I would say the event(s) did happen.

2 Since the event(s), there have been times when my ability to remember the event(s) depends on who I am with AND other times when my ability to remember the event(s) does not depend on who I am with.

9 Since the event(s), there have been times when I think of the event(s) less when I am around people AND other times when I do not think of the event(s) less when I am around people.

\section{Awareness}

6 Since the event(s), there have been times when I didn't believe the event(s) happened AND there have been other times when I believed that it did.

18 Since the event(s), there have been times when I was not aware the event(s) happened AND other times when I was aware the event(s) happened.

15 Since the event(s), there have been times when only part of me was aware the event(s) happened AND other times when all of me was aware the event(s) happened. Since the event(s), there have been times when I knew the event(s) happened but on some level I didn't know AND other times when I fully and completely knew the event(s) happened.

\section{Remembering}

4 Since the event(s), there have been times when the event(s) is readily available for remembering AND

$1.56 \quad 0.80$

$1.48 \quad 0.72$

0.75

$1.63 \quad 0.84$

$1.63 \quad 0.87$

0.81 
other times that the event(s) was not readily available for remembering.

13 Since the event(s), there have been times when I try to remember the event(s) but can't AND other times when I try to remember the event(s) and can.

3 Since the event(s), there have been times when I try to remember the details of the event(s) but can't AND other times when I try to remember the details of the event(s) and can

17 Since the event(s), there have been times when I could always remember the event(s) if I wanted to AND other times when I could not remember the event(s) even if I wanted to.

Note. Each item in the R-BBQ has the stem: "Think back to this same event(s) you reported. Please indicate how much you agree with the following statements SINCE THE EVENT(S)... 
BETRAYAL BLINDNESS QUESTIONNAIRES (BBQs)

Figure 1. Betrayal Trauma Theory, reprinted with permission

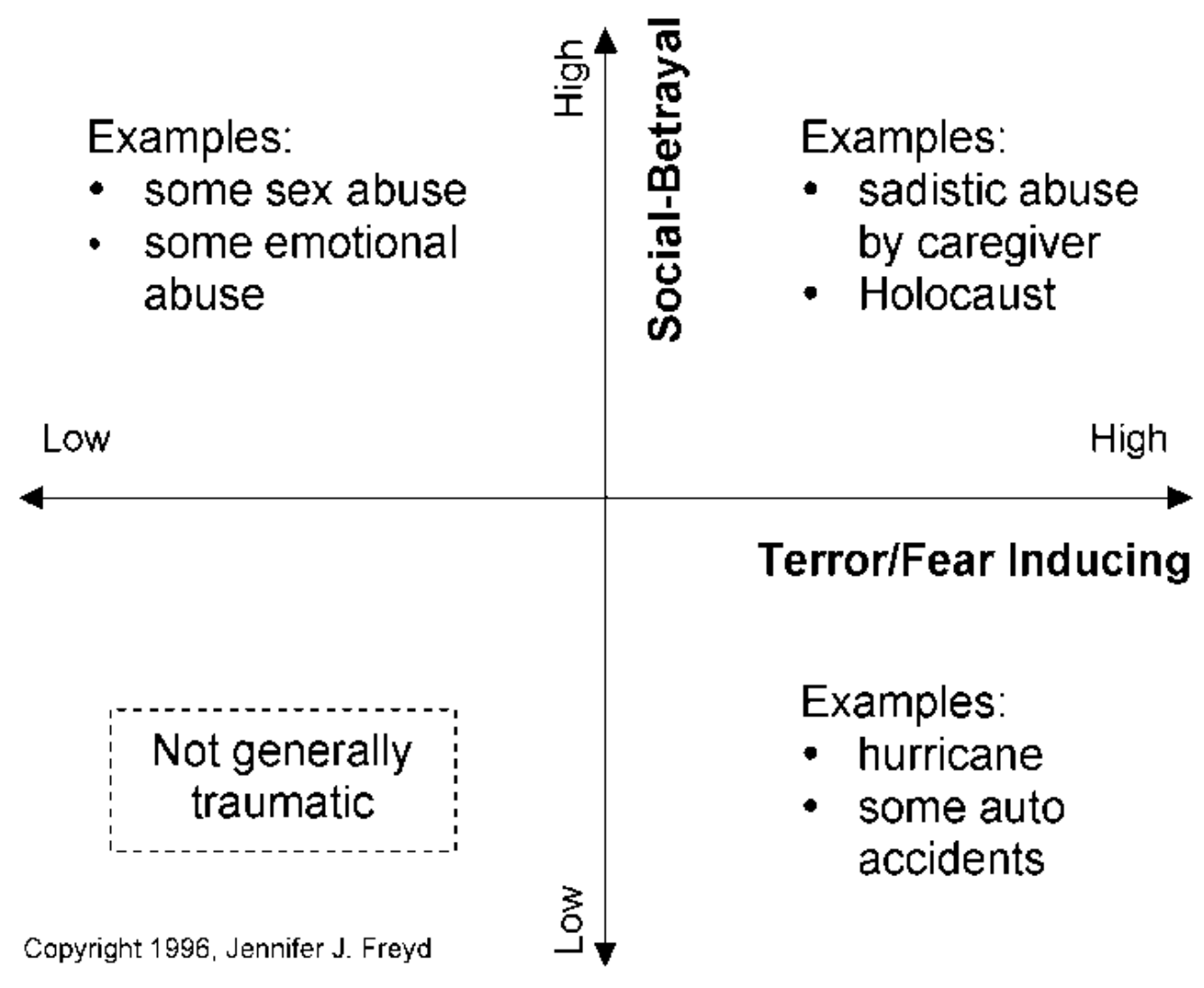

